\title{
An update of clinical characteristics and imaging findings of pulmonary aspergillosis
}

\author{
Shambhu K Sah ${ }^{1}$, Ying $\mathrm{Li}^{1}$, Oormila Ganganah ${ }^{2}$, Xiaoqing $\mathrm{Shi}^{1}$, Yongmei $\mathrm{Li}^{1}$ \\ 1. Department of Radiology, The First Affiliated Hospital, Chongqing Medical University, Chongqing, China. 2. Department \\ of Respiratory Medicine, The First Affiliated Hospital, Chongqing Medical University, Chongqing, China
}

Correspondence: Yongmei Li. Address: Department of Radiology, The First Affiliated Hospital, Chongqing Medical University, No. 1 Youyi Road, Yuzhong District, Chongqing 400016, China. Email: lymzhang70@hotmail.com

Received: J une 20, 2015

Accepted: August 22, 2015

Online Published: September 7, 2015

DOI : $10.5430 /$ ijdi.v3n1p8

URL: http://dx.doi.org/10.5430/ijdi.v3n1p8

\section{Abstract}

Pulmonary aspergillosis (PA) is a clinical spectrum of rapidly progressive potentially fatal opportunistic mycosis usually caused by Aspergillus organisms. In the recent years, the number of patients with invasive pulmonary aspergillosis (IPA) has increased and it remains a major cause of morbidity and mortality in immunocompromised patients. Chest CT plays an important role in the early diagnosis of IPA and should be included in the investigative protocol. Typical imaging findings of IPA include nodule, consolidation, the halo sign, the hypodense sign and the air crescent sign. CT Angiography (CTA) has a higher sensitivity for detecting angioinvasive aspergillosis. However, the diagnosis of pulmonary aspergillosis remains challenging radiologically in immunocompetent chronic obstructive pulmonary disease (COPD) and critically ill patients in intensive care unit (ICU) because of the non-specific CT findings and further studies are needed to establish the confirm diagnosis.

\section{Keywords}

Pulmonary aspergillosis, Clinical characteristics, Imaging findings, Computed tomography

\section{Introduction}

Pulmonary aspergillosis is a clinical spectrum of lung disease caused by opportunistic fungi of Aspergillus species (usually Aspergillus fumigatus, an environmentally ubiquitous filamentous fungus acquired by inhaling its spores). When host immunity is intact, Aspergillus usually does not cause pulmonary pathology, however altered immunity predisposes to lung disease. Pulmonary aspergillosis is classified into aspergilloma (saprophytic aspergillosis), allergic bronchopulmonary aspergillosis (ABPA), semi-invasive or chronic necrotizing pulmonary aspergillosis (CNPA), and invasive pulmonary aspergillosis (IPA). In the recent years, the number of patients with IPA has increased and it remains a major cause of morbidity and mortality in immunocompromised patients. Though chest CT plays an important role in the early diagnosis of IPA, the diagnosis of pulmonary aspergillosis remains challenging radiologically in immunocompetent chronic obstructive pulmonary disease (COPD) and critically ill patients in intensive care unit (ICU) because of the non-specific CT findings and further studies are needed to establish the confirm diagnosis.

In this review, we analyzed the clinical characteristics and imaging findings of the four forms of pulmonary aspergillosis, including the more recently reported aspergillosis associated with COPD and critically ill patients in ICU. 


\section{Aspergilloma (Saprophytic aspergillosis)}

Pulmonary aspergilloma or mycetoma is a saprophytic mass-like fungus ball, usually caused by Aspergillus fumigatus infection without tissue invasion and is common in immunocompetent host. Other fungi associated with formation of a fungal ball are Zygomycetes and Fusarium. The fungus ball is composed of inflammatory cells, fibrin, mucus, tissue debris, and fungal hyphae. Pulmonary aspergilloma occurs in pre-existing pulmonary cavities and tuberculosis (TB) is the most common cause accounting for $75 \%$ of cases ${ }^{[1]}$. Other underlying causes are sarcoidosis, emphysema, bronchiectasis, bronchogenic cyst, pneumoconiosis, fibrotic lung disease, neoplasm, pulmonary infarction, pulmonary sequestration, and Pneumocystis carinii pneumonia (PCP) associated pneumatoceles in acquired immunodeficiency syndrome (AIDS) patients.

Although patients with aspergilloma may remain asymptomatic, the most common symptom is hemoptysis due to surrounding reactive vascular granulation tissue ${ }^{[2]}$. In rare cases, erosion into a bronchial artery may result in life-threatening haemorrhage. Patients may also suffer from cough, sputum production, chest pain, dyspnoea, weight loss and fever secondary to the underlying disease. Aspergilloma may become stable or may grow, causing pneumonia, pulmonary fibrosis and disseminated infections in addition to the obvious symptom of hemoptysis. Bronchial aspergilloma occurs frequently as a pseudotumor and is usually characterized by few, if any, symptoms. Patients with pleural aspergilloma are usually debilitated, if not in obvious cachexia ${ }^{[3]}$.

The diagnosis of pulmonary aspergilloma is established by imaging findings and serological or microbiological evidence of Aspergillus. Aspergilloma is the most common form of pulmonary involvement by Aspergillus seen radiographically. Chest X-ray and CT scan of aspergilloma typically appear as a solid, round or oval mass with soft tissue attenuation within a lung cavity. The mass is separated from the wall of the cavity by crescent of air, resulting in the "air crescent sign" or "monod sign" (see Figure 1). The fungus ball usually moves when the patient changes position from supine to prone ${ }^{[4]}$. Aspergillomas are usually single, but they may also be multiple ones and present bilaterally. They occur predominantly in the posterior segments of the upper lobes and the superior segments of the lower lobes. Pleural thickening adjacent to a pre-existing pulmonary cavity may be the earliest radiographic sign of aspergilloma. These imaging findings may be seen in other conditions such as hydatid cyst, abscess, neoplasm, hematoma and Wegener granulomatosis. However, aspergilloma may also coexist with any of these mentioned conditions. An aspergilloma presenting a mass shadow on imaging may mimic a lung cancer in healthy people with intact immune response ${ }^{[5]}$. Diagnosis of aspergilloma currently relies on cultivation of Aspergillus species from respiratory tract secretions (isolated sputum culture is negative in $50 \%$ of cases) or visualization of hyphae in biopsied tissue (transbronchial biopsies through a fiberoptic bronchoscopy or CT-guided percutaneous trans-thoracic lung biopsies) ${ }^{[3]}$. To improve the relative insensitivity of bronchoalveolar lavage (BAL) fluid culture (40\%-50\%), serum precipating Aspergillus antibodies, bronchial galactomannan enzyme immunoassay (EIA), and quantitative polymerase chain reaction (PCR) assay add sensitivity to the procedure $(94 \%-98 \%)^{[6]}$.
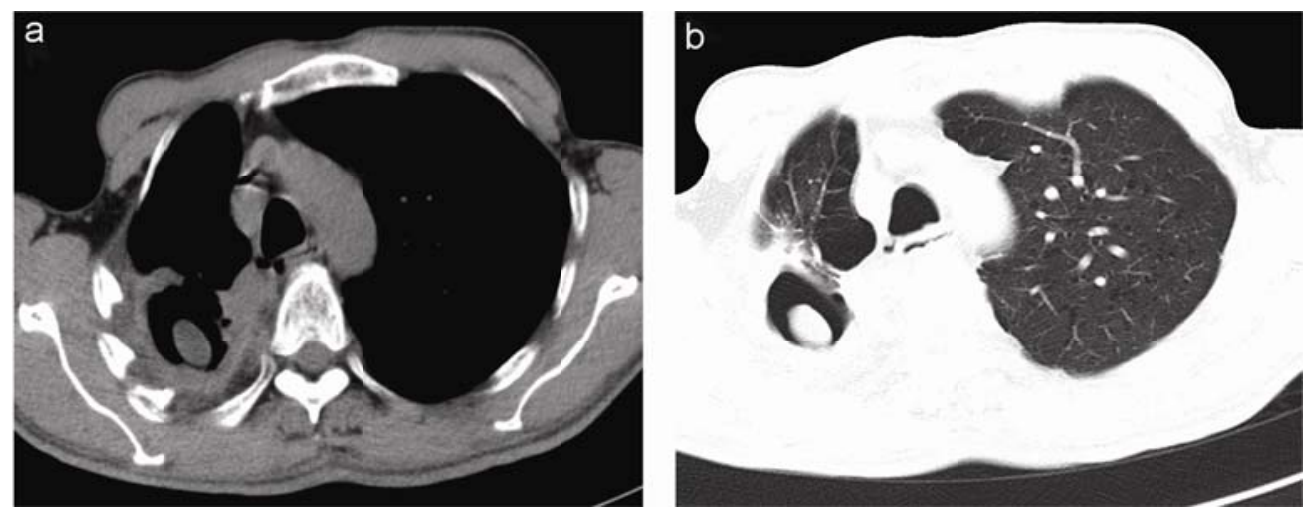

Figure 1. Aspergilloma (fungus ball) in a 59-year-old man with a history of pulmonary tuberculosis. CT-image of "air crescent sign" or "monod sign" in right upper pulmonary lobe viewed by soft tissue window (a) and lung window (b) 


\section{Allergic bronchopulmonary aspergillosis (ABPA)}

ABPA is an allergic or a hypersensitivity response to Aspergillus species (usually A. fumigatus). It is encountered almost exclusively in patients with long-standing bronchial asthma ${ }^{[7]}$ and occasionally in patients with cystic fibrosis. It is estimated that $2 \%$ of asthmatics, and 7\%-14\% of corticosteroid dependent asthmatics have ABPA. Patterson et al. ${ }^{[8]}$ found that the incidence of ABPA is also higher in atopy patients. The incidence of ABPA in case of cystic fibrosis ranges from $1 \%$ to $15 \%{ }^{[9]}$. Although ABPA can occur at any age, it is most common in the third and fourth decades of life.

Clinical manifestations of ABPA are non-specific and may range from recurrent asthma exacerbations with cough, production of sputum containing brown plugs, wheezing, shortness of breath, and pleuritic chest pain to systemic features with low-grade fever, headache, anorexia, and general weakness or malaise ${ }^{[10]}$. ABPA patients can also suffer from allergic conditions such as allergic rhinitis, sinusitis, eczema, and urticaria. Physical examination findings can range from a normal examination to end-stage fibrotic lung disease such as clubbing, cor pulmonale, and fine crackles. Lung examination may reveal crackles or bronchial breath sounds in the presence of pulmonary infiltrates. ABPA is caused by an allergic response characterized by IgE-mediated type I and IgG-mediated type III hypersensitivity reactions to antigens released by Aspergillus organisms ${ }^{[11]}$. The Aspergillus-specific IgE-mediated type I hypersensitivity reaction causes peripheral blood eosinophilia and the specific IgG-mediated type III hypersensitivity reaction causes bronchial wall damage and bronchiectasis ${ }^{[12]}$.

The diagnosis of ABPA is based on a combination of clinical, radiological and immunological criteria; peripheral blood eosinophilia, elevated serum IgE and IgG antibody levels and positive Aspergillus precipitin test ${ }^{[13,14]}$. ABPA is characterized by the presence of fleeting dense plugs of mucus admixed with fungal hyphae and eosinophils resulting into segmental and subsegmental bronchial dilatation. Typical chest X-ray findings of ABPA can be transient (pulmonary infiltrates, consolidation, mucoid impaction) or permanent ("tram lines" and "ring sign" indicating bronchiectasis, parenchymal fibrosis). However, normal chest X-ray appearance does not exclude the diagnosis of ABPA. CT findings in ABPA include fleeting pulmonary infiltrates, bronchial wall thickening, central bronchiectasis, pulmonary fibrosis, and mucoid impaction predominantly in the upper lobes. On chest CT, finger-like opacity (Y-or V-shaped opacity) radiating from the hilum due to mucoid impaction of bronchi is referred to as "gloved finger sign" (see Figure 2). High resolution $\mathrm{CT}$ (HRCT) scan is an excellent imaging investigation to examine bronchiectasis and other radiographic changes due to ABPA that may be missed by conventional CT scan ${ }^{[15]}$.
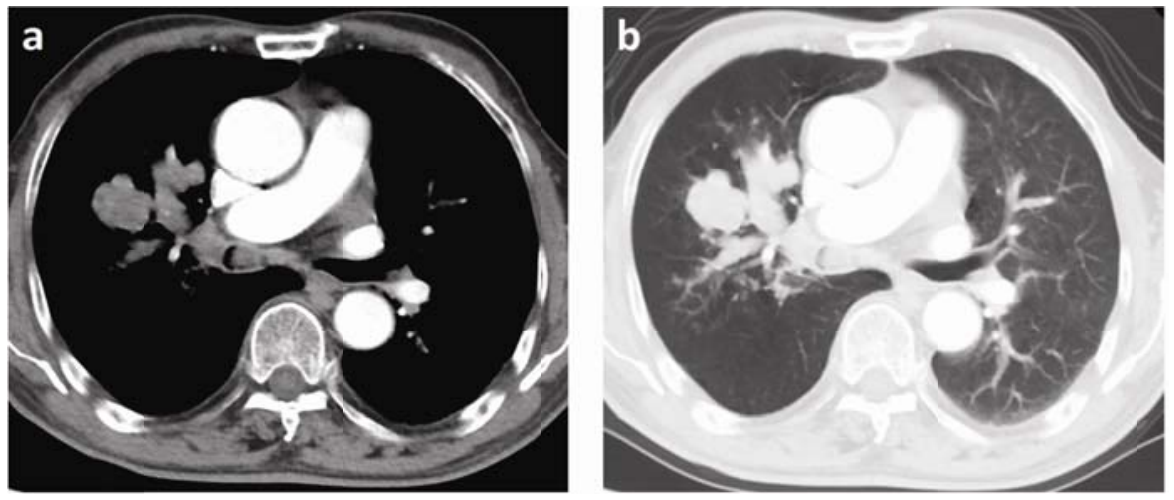

Figure 2. Allergic bronchopulmonary aspergillosis in a 78-year-old asthmatic man. CT-image of "gloved finger sign" in right upper pulmonary lobe viewed by soft tissue window (a) and lung window (b)

\section{Chronic necrotizing pulmonary aspergillosis (CNPA)}

CNPA, also known as semi-invasive or subacute invasive pulmonary aspergillosis, is an indolent pulmonary infectious process usually caused by A. fumigatus. CNPA runs a slowly progressive course over months to years and is associated 
with underlying chronic pulmonary diseases such as COPD, pulmonary infarction, sarcoidosis, pneumoconiosis, cystic fibrosis, previous pulmonary tuberculosis, neoplasm with prior radiation therapy or previous surgery ${ }^{[16,17]}$. In addition, it may also be associated with mildly immune compromised patients due to prolonged corticosteroid therapy, diabetes mellitus, alcoholism, malnutrition, or connective tissue diseases ${ }^{[18]}$. Cases of CNPA have also been described in immunocompetent patients ${ }^{[19]}$. Mannose-binding lectin gene polymorphism plays an important role in the pathogenesis of $\mathrm{CNPA}^{[20]}$. Histologically, CNPA is characterized by necrosis of lung tissue followed by acute or chronic inflammation of the cavity wall and especially the presence of hyphae consistent with Aspergillus species. In contrast to IPA, in CNPA vascular invasion and dissemination to other organs are unusual.

CNPA is common in middle-aged to older individuals and may manifest as chronic cough, sputum production, fever, night sweats, malaise, fatigue, and weight loss that occurs over a period of months. Occasionally, patients may suffer from hemoptysis. However, in rare cases patients may be asymptomatic. Leukocytosis is usually present ${ }^{[21]}$.

Radiologically, CNPA is characterized by chronic cavitary consolidation with adjacent pleural thickening in the upper lobes of lung (see Figure 3). The adjacent pleural thickening may progress to form a bronchopleural fistula which is an early sign of a locally invasive process ${ }^{[22]}$. Multiple nodular areas of increased opacity with progressive cavitation in one or both upper lobes may also be seen. These radiological findings tend to occur over a period of months. Aspergilloma (fungus ball) occurs in nearly half of patients ${ }^{[23]}$. In addition, Dobbertin et al. ${ }^{[24]}$ reported that CNPA and ABPA are sometimes associated with endobronchial aspergillosis. Most of the CNPA patients have positive serum IgG antibodies to Aspergillus ${ }^{[25]}$. Histopatholigical demonstration of Aspergillus on lung biopsy or positive serological results for Aspergillus or the growth of Aspergillus on culture confirms the diagnosis of CNPA ${ }^{[26]}$. Local invasion of the lung tissue without a pre-existing cavity differentiates CNPA from aspergilloma where Aspergillus colonizes a pre-existing cavity.
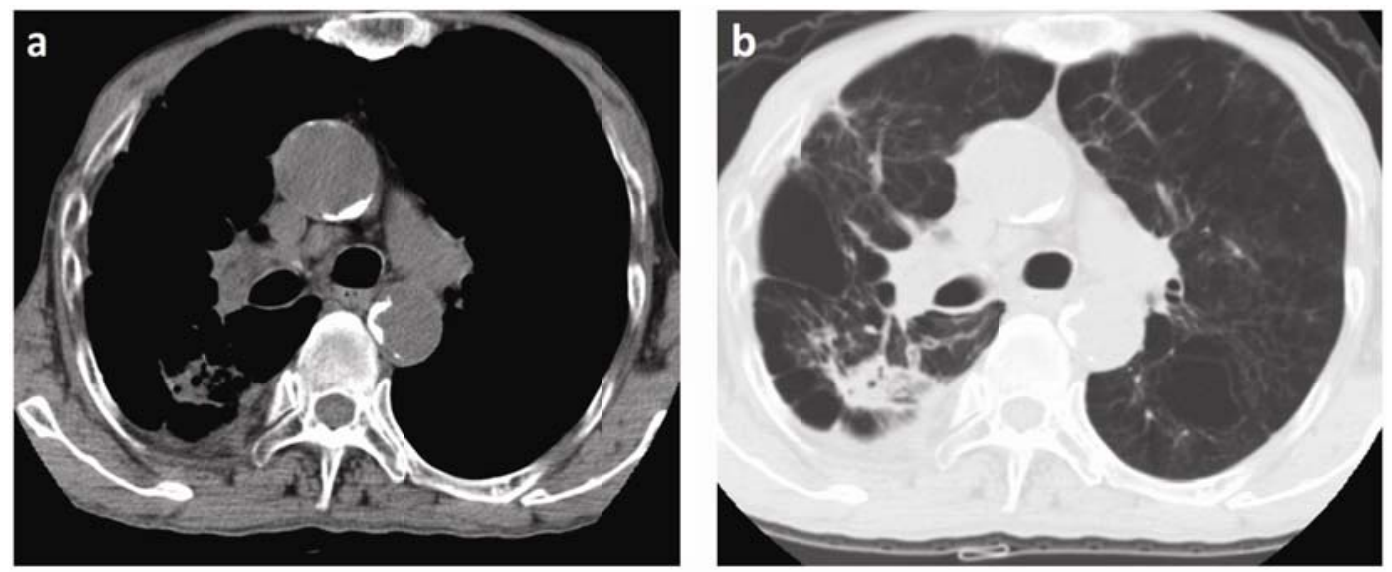

Figure 3. Chronic necrotizing pulmonary aspergillosis in a 75-year-old man with COPD. CT-image of chronic consolidation with adjacent pleural thickening in the right upper pulmonary lobe viewed by soft tissue window (a) and lung window (b)

\section{I nvasive pulmonary aspergillosis (I PA)}

IPA is an aggressive, rapidly progressive potentially fatal opportunistic mycosis in the immunocompromised patient. It is mainly caused by Aspergillus fumigatus, an environmentally ubiquitous filamentous fungus acquired by inhaling its spores. Aspergillus may be found in the hospital ventilation systems. IPA is characterized by the invasion of normal lung tissue by Aspergillus organisms and thereby causing significant tissue damage and necrosis. Dectin-1, the major $\beta$-glucan cell surface receptor present on macrophages, and Toll-like receptors 2 and 4 (TLR2 and TLR4) are involved in immune recognition of A. fumigatus ${ }^{[27,28]}$. The incidence of IPA has increased significantly during the last three decades with the advances in the fields of hematopoietic stem cell and solid organ transplantation, oncology and critical care medicine ${ }^{\text {[29] }}$, including excessive use of aggressive chemotherapy and immunosuppressive agents ${ }^{[30]}$. 
The risk factors of IPA include prolonged neutropenia or immunosuppression, Haematopoietic stem-cell transplantation (HSCT), solid-organ transplantation (SOT), prolonged high-dose corticosteroid therapy, haematological malignancy, cytotoxic therapy, advanced Acquired immunodeficiency syndrome (AIDS), and children with primary immunodeficiency syndromes ${ }^{[21]}$. Two at-risk groups stand out: patients with severe COPD and critically ill patients. Neutropenia with a granulocyte count of $<500$ cells $/ \mu 1$ and a prolonged neutropenic period constitute major risk factors for invasive aspergillosis. Patients with IPA have a poor prognosis with mortality rate of $50 \%-90 \%{ }^{[31]}$. Early diagnosis of the disease is a key consideration for early institution of treatment to achieve a favorable prognosis.

Clinical manifestations are non-specific, however typically manifests as fever unresponsive to antibiotics, cough, sputum production, dyspnea with hypoxia, pleuritic chest pain and hemoptysis. Aspergillus infection may disseminate haematogenously to brain resulting in seizures, meningitis, epidural abscesses, ring-enhancing lesions, cerebral infarctions, and intracranial haemorrhage ${ }^{[25]}$. Involvement of other organs such as pleura, skin, oesophagus, liver, heart and kidneys are also reported ${ }^{[32]}$.

Invasive pulmonary aspergillosis is classified into angioinvasive and airway invasive patterns on the basis of radiological manifestations. Angioinvasive aspergillosis is an aggressive and fatal condition that occurs in profoundly immunocompromised patients with severe neutropenia ${ }^{[33]}$. Histopathologically, it is characterized by fungal invasion in pulmonary vessels substantially causing tissue necrosis and systemic dissemination to central nervous system (CNS), gastrointestinal tract (GIT), and kidneys ${ }^{[34]}$. The clinical diagnosis of angioinvasive aspergillosis is challenging and leads to high mortality rate.

Airway invasive aspergillosis is an uncommon invasive disease mostly affecting the airways of the respiratory tract by Aspergillus organisms. It is frequently seen in immunocompromised and AIDS patients ${ }^{[35]}$. The airway invasive pattern is more common in SOT recipients $(65 \%)$ than in neutropenic patients $(7 \%)$ with IPA ${ }^{[36]}$. Histopathologically, it is characterized by fungal invasion deep into the airway basement membrane. Clinically, it includes acute tracheobronchitis, bronchiolitis, and bronchopneumonia. Bronchoscopic examination with microscopic sampling and culture of the biopsy specimens appears to have a high diagnostic yield for Aspergillus tracheobronchitis in immunocompromised patients ${ }^{[37]}$. Histopathologic demonstration of Aspergillus-like hyphae invading bronchial mucosa gives a definite diagnosis. Endobronchial ultrasound-guided transbronchial needle aspiration may be useful to achieve diagnosis in thrombocytopenic patients with the lowest risk of bleeding.

Chest radiographic features are non-specific. Typical CT findings of early angioinvasive aspergillosis is solitary or multiple nodules and/or peripheral wedge-shaped consolidations with a surrounding halo of haemorrhage seen as an area of ground-glass attenuation (halo sign). With the progression of disease the nodules may cavitate and the central necrotic tissue detaches from the adjacent lung parenchyma resulting in the air crescent sign ${ }^{[38]}$. Nodule is defined as an ovoid soft-tissue opacity measuring $<3 \mathrm{~cm}$ in diameter. An opaciated area obscuring the underlying vessels is referred to as consolidation. For the diagnosis of angioinvasive aspergillosis in neutropenic patients, the overall sensitivity of the multislice CT-angiography (CTA) sign (vessel occlusion) was $86.4 \%$ and the specificity $92.0 \%$. Whereas, the classical halo sign had a sensitivity of only $36.4 \%$ and a specificity of $84.0 \%$ indicating that the CTA sign has a higher sensitivity than the classical CT-signs to detect angioinvasive aspergillosis ${ }^{[39]}$. Airway invasive aspergillosis are non-specific, however typically presented as tracheal or bronchial wall thickening in obstructive tracheobronchitis due to aspergillosis, centrilobular nodules and areas of "tree-in-bud" appearance (an opacified segment of small branching bronchioles) in Aspergillus bronchiolitis, and patchy peribronchial consolidation in Aspergillus bronchopneumonia ${ }^{[12]}$.

The chest CT "halo sign" is referred to a circular area of ground-glass attenuation surrounding a pulmonary nodule or mass with central soft-tissue attenuation (see Figure 4). The pathophysiologic mechanism of the halo sign corresponds to a central area of infarction and coagulative necrosis surrounded by alveolar hemorrhage. The halo sign is a useful finding for early diagnosis of IPA. The halo sign is more common in patients with IPA affecting haematological patients (48\%-76\%) 
than in patients with IPA after SOT $(30 \%)^{[40]}$. Although the halo sign is seen most commonly in the IPA, it is relatively non-specific as it may also accompany with eosinophilic pneumonia, organizing pneumonia, bronchiolitis obliterans, candidiasis, coccidioidomycosis, herpes simplex and cytomegalovirus infection, Wegener granulomatosis, Kaposi sarcoma, bronchoalveolar carcinoma, lymphoma and metastatic angiosarcoma ${ }^{[41]}$. Lung infections due to Candida, Cryptococcus and Coccidioides species may also manifest with a halo sign on a chest CT scan ${ }^{[42]}$.
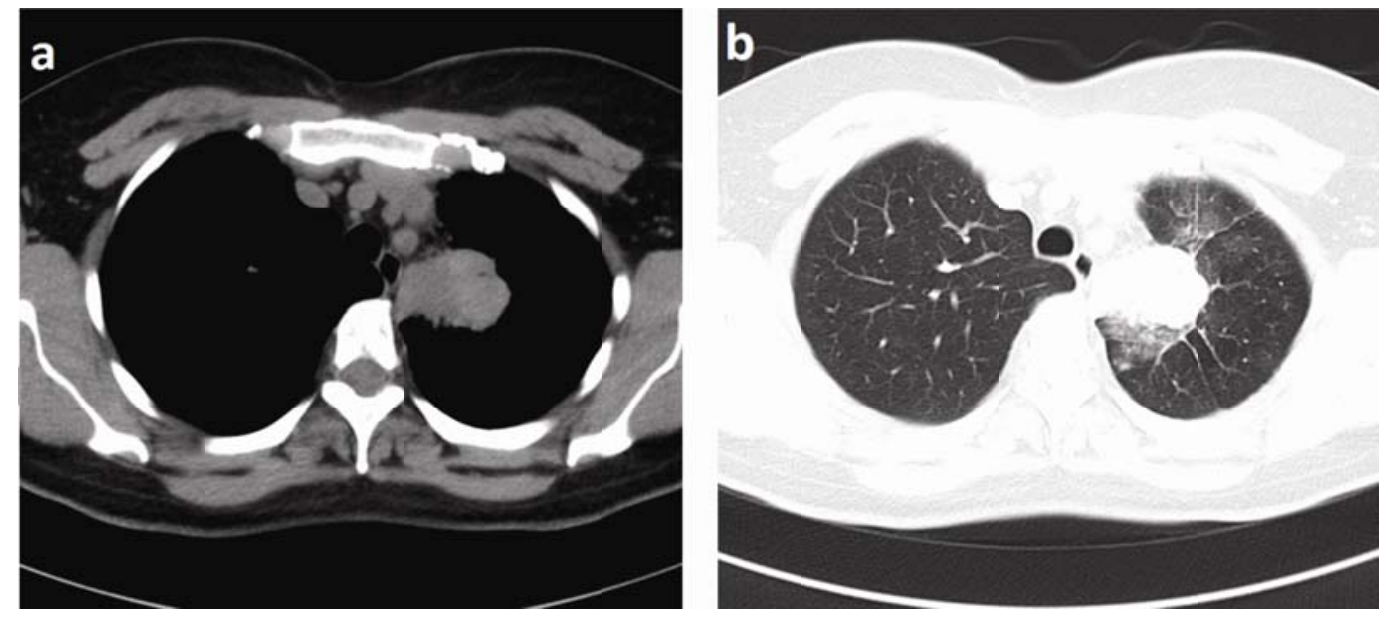

Figure 4. Invasive pulmonary aspergillosis in a 52-year-old female with cervix carcinoma and severe neutropenia after chemotherapy. CT-image of "halo sign" in left upper pulmonary lobe viewed by soft tissue window (a) and lung window (b)

Reversed halo sign (RHS) or atoll sign can also be seen in IPA ${ }^{[43]}$. The RHS is defined as a focal, rounded area of ground-glass opacity surrounded by a nearly complete ring of consolidation. It has been reported that the central ground-glass opacity corresponds histopathologically to the area of alveolar septal inflammation and cellular debris and the peripheral ring of consolidation corresponds to the area of organizing pneumonia within the alveolar ducts. The RHS is regarded as a non-specific sign that can be encountered in many pulmonary conditions, including infectious conditions such as paracoccidioidomycosis, tuberculosis, histoplasmosis, and invasive fungal pneumonia; and non-infectious conditions including Wegener's granulomatosis, lymphomatoid granulomatosis, and sarcoidosis.

In a retrospective analysis of serial unenhanced CT scans of 43 immunocompromised patients with IPA, Horger et al. ${ }^{[44]}$ revealed another imaging finding called the "hypodense" sign (central hypointensity) in lung consolidations or nodules. It is thought to be caused by vascular obstruction with secondary lung infarction and sequestration, finally resulting in cavitation or lesion resolution. Hence, the hypodense sign proved to be a precursor of the crescent sign, anticipating it by a range of 2-19 days. The hypodense sign was reported in 13 (30.2\%) out of 43 patients with IPA. This sign was generally detected after the initial presentation of radiographic finding of a halo sign substantially limiting its application for early diagnosis of IPA.

"Air crescent sign" is a crescent shaped air density within a mass or nodular opacity resulting from air accumulation between the mass or nodule and normal lung parenchyma (see Figure 4b). It is seen most commonly in neutropenic or immunocompromised patients with aspergillosis. It develops days to weeks after infection when neutrophils increase in number and separate necrotic tissue from the normal lung parenchyma filling with air. It is a sign of recovery in the resolving phase of infection, when neutropenia in the peripheral blood is improving with a favorable prognosis when associated with early institution of treatment. The absence of the air crescent sign is associated to a survival rate decreased by 3 months ${ }^{[45]}$. The other causes of air crescent sign are mycetoma, hematoma, hydatid cyst with bronchial involvement, abscess, necrotizing pnaeumonia, cystic bronchiectasis filled with mucus plugs and papillomatosis ${ }^{[46]}$. 
Milito et al. ${ }^{[47]}$ observed that the most frequent CT findings of IPA in patients with hematologic malignancies are peripheral nodular lesions, regardless of the mechanism of immunosuppression. CT findings of IPA in non-hematological patients frequently manifested as acute bronchopneumonia, and the common findings include ground-glass opacities and air-space consolidations. Consolidation or mass is the most common CT finding of IPA in solid organ transplantation (SOT) recipients and presence of small cavities may be associated with favorable prognosis ${ }^{[48]}$. Zaspel et al. ${ }^{[49]}$ identified characteristic radiological appearance of IPA in HIV patients as nodules (92\%), cavitations (75\%), air crescent sign (33\%) or subpleural infarctions (17\%). Thick-walled cavitary lesions were demonstrated as a late finding in late-stage AIDS with a CD4 cell count of $<5 / \mathrm{mm}^{3}{ }^{[50]}$. Radiologic manifestations of invasive aspergillosis in case of children include segmental and multilobar consolidation, perihilar infiltrates, multiple small nodules, peripheral nodular masses and pleural effusions ${ }^{[51]}$.

In the recent years, the number of studies has been reported that the incidence of IPA is gradually increasing in nonneutropenic immunocompetent COPD and critically ill patients in ICU ${ }^{[52,53]}$. In COPD patients ciliary activity impairment, immunosuppression due to alveolar macrophage and neutrophil inhibition in those treated with steroids and also receiving broad-spectrum antibiotics, play an important role in the development of IPA ${ }^{[54]}$. The most common invasive aspergillosis-associated underlying disease in ICUs is COPD, followed by SOT ${ }^{[33]}$. The most frequent chest X-ray and CT finding in IPA patients with COPD was infiltration ${ }^{[55]}$. Diagnosis of IPA in the ICU is not straightforward and may be delayed by several days due to the lack of clinical suspicion. IPA in ICU patients is associated with high mortality and hospital costs. Imaging is usually non-specific, showing consolidation, patchy infiltrates, cavitation or nodules, and may be complicated by coexisting findings like atelectasis, pleural effusions or adult respiratory distress syndrome.

Obstructive bronchopulmonary aspergillosis (OBPA) is a rare non-invasive aspergillosis usually caused by intraluminal overgrowth of A. fumigatus, in AIDS patients ${ }^{[56]}$. Clinical manifestations are non-specific, however may present as fever, cough, dyspnea with hypoxia. CT findings in OBPA include bilateral bronchial and bronchiolar dilatation, mucoid impaction in lower lobes and diffuse lower lobe consolidation caused by postobstructive atelectasis ${ }^{[56]}$.

In a recently published case report of invasive aspergillosis in patient with acute myeloid leukemia, Dynamic contrast-enhanced magnetic resonance imaging (DCE-MRI) revealed multiple cavitary lesions of various sizes in both lungs. The lesions were isointense to hypointense on T1-weighted images (T1WI) compared with muscle tissue; on T2-weighted images (T2WI), the center of the lesions was hyperintense, the walls were thick and showed isointensity to hypointensity. In diffusion-weighted images (DWI), lesion walls showed restricted diffusion. In postcontrast phase dynamic contrast images, lesion walls showed enhanced contrast (wash in $80 \%-90 \%$ ), and there was no washout in late-phase images ${ }^{[57]}$.

Although chest CT scan has been advocated as a key consideration in the early diagnosis of IPA, none of the signs is sensitive or pathognomic. The most recent advances in the diagnosis of IPA are related to detecting Aspergillus antigens in body fluids, mainly galactomannan and serum $(1 \rightarrow 3)$ - $\beta$-D-glucan (both are polysaccharide components of the fungal cell wall). Both galactomannan and serum $(1 \rightarrow 3)$ - $\beta$-D-glucan assays have received FDA (US Food and Drug Administration) approval and are highly sensitive and specific tests for IPA ${ }^{[58,59]}$. A recent meta-analysis reports that bronchoalveolar lavage (BAL) galactomannan testing with an overall sensitivity and specificity of more than $90 \%$ for the diagnosis of invasive aspergillosis ${ }^{[59]}$. In addition, PCR-based methods to diagnose IPA have also been evaluated by detecting Aspergillus DNA in BAL fluid and serum ${ }^{[60]}$. However, PCR is often associated with false-positive results and is not considered as a routine clinical test. The gold standard for the diagnosis of IPA remains the histopathological demonstration of fungal invasion in lung tissue.

The imaging findings of different forms of pulmonary aspergillosis are summarized in Table 1. 
Table 1. Summary of the imaging findings of pulmonary aspergillosis

\begin{tabular}{|c|c|}
\hline Disease & Imaging findings \\
\hline $\begin{array}{l}\text { Aspergilloma } \\
\text { (Saprophytic } \\
\text { aspergillosis) }\end{array}$ & $\begin{array}{l}\text { Chest X-ray \& CT: } \\
\text { A lung cavity containing a solid, round or oval mass which is separated from the wall by a crescent of } \\
\text { air, resulting in the "air crescent" sign. } \\
\text { Thickening of the cavity wall and the adjacent pleura. } \\
\text { This fungus ball may be mobile. }\end{array}$ \\
\hline $\begin{array}{l}\text { Allergic } \\
\text { bronchopulmonary } \\
\text { aspergillosis (ABPA) }\end{array}$ & $\begin{array}{l}\text { Chest X-ray: It can be transient (pulmonary infiltrates, consolidation, mucoid impaction) or permanent } \\
\text { ("tram lines" and "ring sign" indicating bronchiectasis, parenchymal fibrosis). } \\
\text { CT: Finger-like opacity in a bronchial distribution representing mucus plugging within bronchiectasis } \\
\text { ("gloved finger sign"), predominantly involving the upper lobes. }\end{array}$ \\
\hline $\begin{array}{l}\text { Chronic necrotizing } \\
\text { pulmonary aspergillosis } \\
\text { (CNPA) }\end{array}$ & $\begin{array}{l}\text { Chest X-ray \& CT: } \\
\text { Chronic cavitary consolidation with adjacent pleural thickening in the upper lobes of lung. } \\
\text { The adjacent pleural thickening may progress to form a bronchopleural fistula which is an early sign of } \\
\text { a locally invasive process. }\end{array}$ \\
\hline $\begin{array}{l}\text { Invasive Pulmonary } \\
\text { Aspergillosis (IPA) }\end{array}$ & $\begin{array}{l}\text { Angioinvasive aspergillosis: } \\
\text { CT: Nodules or consolidations surrounded by a ground-glass halo ("Halo sign”), progressing to } \\
\text { cavitation or air crescent formation (“Air crescent sign"). } \\
\text { CTA: Vessel occlusion } \\
\text { DCE-MRI: Multiple cavitary lesions of various sizes in both lungs. The lesions were isointense to } \\
\text { hypointense on T1WI compared with muscle tissue; on T2WI, the center of the lesions was } \\
\text { hyperintense, the walls were thick and showed isointensity to hypointensity. In DWI, lesion walls } \\
\text { showed restricted diffusion. In postcontrast phase dynamic contrast images, lesion walls showed } \\
\text { enhanced contrast and there was no washout in late-phase images. } \\
\text { The most frequent chest X-ray and CT finding in IPA patients with COPD was infiltration. } \\
\text { Airway invasive aspergillosis: } \\
\text { CT: Tracheal or bronchial wall thickening in obstructive tracheobronchitis due to aspergillosis, } \\
\text { centrilobular nodules and areas of "tree-in-bud" appearance in aspergillus bronchiolitis, and patchy } \\
\text { peribronchial consolidation in aspergillus bronchopneumonia. }\end{array}$ \\
\hline $\begin{array}{l}\text { Obstructive } \\
\text { bronchopulmonary } \\
\text { aspergillosis (OBPA) }\end{array}$ & $\begin{array}{l}\text { CT: Bilateral bronchial and bronchiolar dilatation, mucoid impaction in lower lobes and diffuse lower } \\
\text { lobe consolidation caused by postobstructive atelectasis. }\end{array}$ \\
\hline
\end{tabular}

\section{Conclusion}

Pulmonary aspergillosis is a clinical spectrum of rapidly progressive potentially fatal opportunistic mycosis and is frequently seen in immunocompromised patients. Chest CT plays a key role in the early diagnosis of PA and should be included in the investigative protocol in immunocompromised patients even when plain chest radiographs are normal or non-specific in order to improve patient outcomes with early institution of treatment. Multislice CTA is an excellent imaging investigation to examine vascular occlusion for the diagnosis of angioinvasive aspergillosis in neutropenic patients. However, CT findings are non-specific in immunocompetent COPD and critically ill patients in ICU making the diagnosis of PA challenging radiologically and further studies are needed to establish the confirm diagnosis. DCE-MRI limits radiation exposure and aids in the characterization and assessment of contrast uptake dynamics of lesions, making it a beneficial for evaluating pathologies of the PA. The gold standard in the diagnosis of pulmonary aspergillosis is the histopathological demonstration of fungal invasion in lung tissue, yet obtaining a lung biopsy remains challenging in immunocompromised patients.

\section{Acknowledgements}

This study was supported by National Key Clinical Specialties Construction Program of China (No. 2013-544). 


\section{References}

[1] Khan MA, Dar AM, Kawoosa NU, et al. Clinical profile and surgical outcome for pulmonary aspergilloma: Nine year retrospective observational study in a tertiary care hospital. Int J Surg. 2011; 9: 267-71. PMid:21252003

http://dx.doi.org/10.1016/j.ijsu.2011.01.002

[2] Faruqi S, Hughes D, Chauhan S, et al. Intern Med J. 2009; 39: 64-66. PMid:19290986

http://dx.doi.org/10.1111/j.1445-5994.2008.01810.x

[3] Passera E, Rizzi A, Robustellini M, et al. Pulmonary aspergilloma: clinical aspects and surgical treatment outcome. Thorac Surg Clin. 2012; 22: 345-61. PMid:22789598 http://dx.doi.org/10.1016/j.thorsurg.2012.04.001

[4] Roberts CM, Citron KM, Strickland B. Intrathoracic aspergilloma: role of CT in diagnosis and treatment. Radiology. 1987; 165(1): 123-8. PMid:3628758 http://dx.doi.org/10.1148/radiology.165.1.3628758

[5] Yasuda M, Nagashima A, Haro A, et al. Aspergilloma mimicking a lung cancer. Int J Surg Case Rep. 2013; 4: 690-2. PMid:23792483 http://dx.doi.org/10.1016/j.ijscr.2013.02.028

[6] Musher B, Fredricks D, Leisenring W, et al. Aspergillus galactomannan enzyme immunoassay and quantitative PCR for diagnosis of invasive aspergillosis with bronchoalveolar lavage fluid. J Clin Microbiol. 2004; 42: 5517-22. PMid:15583275 http://dx.doi.org/10.1128/JCM.42.12.5517-5522.2004

[7] Greenberger PA. When to suspect and work up allergic bronchopulmonary aspergillosis. Ann Allergy Asthma Immunol. 2013; 111: 1-4. PMid:23806451 http://dx.doi.org/10.1016/j.anai.2013.04.014

[8] Patterson K, Strek ME. Allergic bronchopulmonary aspergillosis. Proc Am Thorac Soc. 2010; 7: 237-44. PMid:20463254 http://dx.doi.org/10.1513/pats.200908-086AL

[9] Agarwal R. Allergic bronchopulmonary aspergillosis. Chest. 2009; 135: 805-26. PMid:19265090 http://dx.doi.org/10.1378/chest.08-2586

[10] Safirstein BH, D'Souza MF, Simon G, et al. Five-year follow-up of allergic bronchopulmonaryaspergillosis. Am Rev Respir Dis. 1973; 108: 450-59. PMid:4126802

[11] Greenberger PA, Bush RK, Demain JG, et al. Allergic bronchopulmonary aspergillosis. J Allergy Clin Immunol Pract. 2014; 2: 703-8. PMid:25439360 http://dx.doi.org/10.1016/j.jaip.2014.08.007

[12] Franquet T, Muller NL, Gimenez A, et al. Spectrum of pulmonary aspergillosis: histologic, clinical, and radiologic findings. Radio Graphics. 2001; 21: 825-37. PMid:11452056 http://dx.doi.org/10.1148/radiographics.21.4.g01j103825

[13] Agarwal R, Maskey D, Aggarwal AN, et al. Diagnostic performance of various tests and criteria employed in allergic bronchopulmonary aspergillosis: a latent class analysis. PLoS One. 2013; 8: e61105. PMid:23593402 http://dx.doi.org/10.1371/journal.pone.0061105

[14] Dhooria S, Agarwal R. Diagnosis of allergic bronchopulmonary aspergillosis: a case-based approach. Future Microbiol. 2014; 9: 1195-208. PMid:25405888 http://dx.doi.org/10.2217/fmb.14.74

[15] Johkoh T, Müller NL, Akira M, et al. Eosinophilic lung diseases: diagnostic accuracy of thin-section CT in 111 patients. Radiology. 2000; 216: 773-80. PMid:10966710 http://dx.doi.org/10.1148/radiology.216.3.r00se01773

[16] Tashiro T, Izumikawa K, Tashiro M, et al. A Case Series of Chronic Necrotizing Pulmonary Aspergillosis and a New Proposal. Jpn J Infect Dis. 2013; 66: 312-6. PMid:23883842 http://dx.doi.org/10.7883/yoken.66.312

[17] Nam HS, Jeon K, Um SW, et al. Clinical characteristics and treatment outcomes of chronic necrotizing pulmonary aspergillosis: a review of 43 cases. Int J Infect Dis. 2010; 14: e479-82. PMid:19910234 http://dx.doi.org/10.1016/j.ijid.2009.07.011

[18] Segal BH. Aspergillosis. N Engl J Med. 2009; 360: 1870-84. PMid:19403905 http://dx.doi.org/10.1056/NEJMra0808853

[19] Jin E, Wang LM, Li QY, et al. Chronic necrotizing pulmonary aspergillosis in an immunocompetent patient: report of a rare case. Infection. 2014; 42: 565-8. PMid:24381139 http://dx.doi.org/10.1007/s15010-013-0575-z

[20] Crosdale DJ, Poulton KV, Ollier WE, et al. Mannose-binding lectin gene polymorphisms as a susceptibility factor for chronic necrotizing pulmonary aspergillosis. J Infect Dis. 2001; 184: 653-6. PMid:11474427 http://dx.doi.org/10.1086/322791

[21] Gefter WB. The spectrum of pulmonary aspergillosis. J Thorac Imaging. 1992; 7:56-74. PMid:1404546 http://dx.doi.org/10.1097/00005382-199209000-00009

[22] Kim SY, Lee KS, Han J, et al. Semiinvasive pulmonary aspergillosis: CT and pathologic findings in six patients. AJR Am J Roentgenol. 2000; 174: 795-798. PMid:10701627 http://dx.doi.org/10.2214/ajr.174.3.1740795

[23] Lovrenski A, Panjković M, Eri Z, et al. Chronic necrotizing pulmonary aspergillosis. Vojnosanit Pregl. 2011 ; 68: 988-91. PMid:22191319 http://dx.doi.org/10.2298/VSP1111988L

[24] Dobbertin I, Friedel G, Jaki R, et al. Bronchial aspergillosis. Pneumologie. 2010; 64: 171-83. PMid:20072959 http://dx.doi.org/10.1055/s-0029-1215306 
[25] Kousha M, Tadi R, Soubani AO. Pulmonary aspergillosis: a clinical review. Eur Respir Rev. 2011; 20: 156-74. PMid:21881144 http://dx.doi.org/10.1183/09059180.00001011

[26] Zmeili OS, Soubani AO. Pulmonary aspergillosis: a clinical update. QJM. 2007; 100: 317-34. PMid:17525130 http://dx.doi.org/10.1093/qjmed/hcm035

[27] Park SJ, Mehrad B. Innate immunity to Aspergillus species. Clin Microbiol Rev. 2009; 22: 535-51. PMid:19822887 http://dx.doi.org/10.1128/CMR.00014-09

[28] Chai LY, Netea MG, Vonk AG, et al. Fungal strategies for overcoming host innate immune response. Med Mycol. 2009; 47: 227-36. PMid:18654922 http://dx.doi.org/10.1080/13693780802209082

[29] Vandewoude K, Vogelaers D, Blot S. Aspergillosis in the ICU-the new 21st century problem. Med Mycol. 2006 ; $44:$ 71-76. http://dx.doi.org/10.1080/13693780600919262

[30] Chamilos G, Luna M, Lewis RE, et al. Invasive fungal infections in patients with hematologic malignancies in a tertiary care cancer center: an autopsy study over a 15-year period (1989-2003). Haematologica. 2006; 91: 986-9. PMid:16757415

[31] Baddley JW, Andes DR, Marr KA, et al. Factors associated with mortality in transplant patients with invasive aspergillosis. Clin Infect Dis. 2010; 50: 1559-67. PMid:20450350 http://dx.doi.org/10.1086/652768

[32] Denning DW. Invasive aspergillosis. Clin Infect Dis. 1998; 26: 781-803. PMid:9564455 http://dx.doi.org/10.1086/513943

[33] Nootigattu VK, Sundaram J, Shabbani A, et al. Angioinvasive aspergillosis. Arch Dis Child. 2004; 89: 784. PMid:15269084 http://dx.doi.org/10.1136/adc.2003.046599

[34] Shaikh AG, Sundararajan S. Angioinvasive Aspergillosis of the Central Nervous System. Can J Neurol Sci. $2014 ; 19$ : 1-2.

[35] Brown MJ, Worthy SA, Flint JDA, et al. Invasive aspergillosis in the immunocompromised host: utility of computed tomography and bronchoalveolar lavage. Clin Radiol. 1998; 53: 255-57. http://dx.doi.org/10.1016/S0009-9260(98)80122-0

[36] Park SY, Kim SH, Choi SH, et al. Clinical and radiological features of invasive pulmonary aspergillosis in transplant recipients and neutropenic patients. Transpl Infect Dis. 2010; 12: 309-15. PMid:20202177 http://dx.doi.org/10.1111/j.1399-3062.2010.00499.x

[37] Fernández-Ruiz M, Silva JT, San-Juan R, et al. Aspergillus Tracheobronchitis Report of 8 Cases and Review of the Literature. Medicine. 2012; 91: 261-73. PMid:22932790 http://dx.doi.org/10.1097/MD.0b013e31826c2ccf

[38] Sebastianes PM, Fortes M, Meirelles GS. Angioinvasive aspergillosis with halo sign on computed tomography of the lungs. Rev Soc Bras Med Trop. 2008; 41: 219-20. PMid:18545851 http://dx.doi.org/10.1590/S0037-86822008000200020

[39] Stefan Sonnet. Diagnosis of invasive pulmonary aspergillosis with multislice CT-angigraphy. Chest. $2005 ; 128$.

[40] Marchiori E, Irion KL. Commentary on: "Analysis of initial and follow-up CT findings in patients with invasive pulmonary aspergillosis after solid organ transplantation”. Clin Radiol. 2012; 67: 1153-4. PMid:22748676

http://dx.doi.org/10.1016/j.crad.2012.05.004

[41] Pinto PS. Signs in imaging: the CT halo sign. Radiology. 2004; 230: 109-10. PMid:14695389 http://dx.doi.org/10.1148/radiol.2301020649

[42] Kami M, Kishi Y, Hamaki T, et al. The value of the chest computed tomography halo sign in the diagnosis of invasive pulmonary aspergillosis. An autopsy-based retrospective study of 48 patients. Mycoses. 2002; 45: 287-94. PMid:12572717 http://dx.doi.org/10.1046/j.1439-0507.2002.00770.x

[43] Walsh S, Tunnicliffe G. Importance of the reversed halo sign for the diagnosis of angioinvasive pulmonary aspergillosis. Respir Med. 2014; 108: 1240. PMid:25044279 http://dx.doi.org/10.1016/j.rmed.2014.05.003

[44] Horger M, Einsele H, Schumacher U, et al. Invasive pulmonary aspergillosis: frequency and meaning of the "hypodense sign" on unenhanced CT. Br J Radiol. 2005; 78: 697-703. PMid:16046420 http://dx.doi.org/10.1259/bjr/49174919

[45] Caillot D, Mannone L, Cuisenier B, et al. Role of earlydiagnosis and aggressive surgery in the management of invasive pul-monary aspergillosis in neutropenic patients. Clin Microbiol Infect. 2001; 7 (Suppl 2): 54-61. PMid:11525219 http://dx.doi.org/10.1111/j.1469-0691.2001.tb00010.x

[46] Hansell DV, Armstrong P, Lynch DA, et al. Basic patterns in lung disease. In: Hansell DV, Armstrong P, Lynch DA, McAdams HP. Imaging of diseases of the chest. 4th ed. Philadelphia: Lippincott Williams \& Williams. 2005; 69-142.

[47] Milito MA, Kontoyiannis DP, Lewis RE, et al. Influence of host immunosuppression on CT findings in invasive pulmonary aspergillosis. Med Mycol. 2010; 48: 817-23. PMid:20109093 http://dx.doi.org/10.3109/13693780903514872

[48] Lim C, Seo JB, Park SY, et al. Analysis of initial and follow-up CT findings in patients with invasive pulmonary aspergillosis after solid organ transplantation. Clin Radiol. 2012; 67: 1179-86. PMid:22766482 http://dx.doi.org/10.1016/j.crad.2012.02.018

[49] Zaspel U, Denning DW, Lemke AJ, et al. Diagnosis of IPA in HIV: the role of the chest X-ray and radiologist. Eur Radiol. 2004; 14: 2030-7. PMid:15309496 http://dx.doi.org/10.1007/s00330-004-2447-5

[50] Kenney HH, Agrons GA, Shin JS. Best cases from the AFIP. Invasive pulmonary aspergillosis: radiologic and pathologic findings. Radiographics. 2002; 22: 1507-10. PMid:12432119 http://dx.doi.org/10.1148/rg.226025101 
[51] Thomas KE, Owens CM, Veys PA, et al. The radiological spectrum of invasive aspergillosis in children: a 10-year review. Pediatr Radiol. 2003; 33: 453-60. PMid:12739082 http://dx.doi.org/10.1007/s00247-003-0919-4

[52] Guinea J, Torres-Narbona M, Gijón P, et al. Pulmonary aspergillosis in patients with chronic obstructive pulmonary disease: incidence, risk factors, and outcome. Clin Microbiol Infect. 2010; 16: 870-7. PMid:19906275 http://dx.doi.org/10.1111/j.1469-0691.2009.03015.x

[53] Blot SI, Taccone FS, Van den Abeele A-M, et al. A clinical algorithm to diagnose invasive pulmonary aspergillosis in critically ill patients. Am J Respir Crit Care Med. 2012; 186: 56-64. PMid:22517788 http://dx.doi.org/10.1164/rccm.201111-19780C

[54] Philippe B, Ibrahim-Granet O, Prévost MC, et al. Killing of Aspergillusfumigatus by alveolar macrophages is mediated by reactive oxidant intermediates. Infect Immun. 2003; 71: 3034-42. PMid:12761080 http://dx.doi.org/10.1128/IAI.71.6.3034-3042.2003

[55] Tutar N, Metan G, Koç AN, et al. Invasive pulmonary aspergillosis in patients with chronic obstructive pulmonary disease. Multidiscip Respir Med. 2013; 8: 59. PMid:24135224 http://dx.doi.org/10.1186/2049-6958-8-59

[56] Miller WT Jr, Sais GJ, Frank I, et al. Pulmonary aspergillosis in patients with AIDS: clinical and radiographic correlations. Chest. 1994; 105: 37-44. http://dx.doi.org/10.1378/chest.105.1.37

[57] Araz Ö, Karaman A, Ucar EY, et al. DCE-MRI findings of invasive aspergillosis in patient with acute myeloid leukemia. Clin Respir J. 2014; 8: 248-50. PMid:24118929 http://dx.doi.org/10.1111/crj.12061

[58] Koo S, Bryar JM, Page JH, et al. Diagnostic performance of the $(1 \rightarrow 3)$-beta-Dglucan assay for invasive fungal disease. Clin Infect Dis. 2009; 49: 1650-9. PMid:19863452 http://dx.doi.org/10.1086/647942

[59] Guo YL, Chen YQ, Wang K, et al. Accuracy of BAL galactomannan in diagnosing invasive aspergillosis: a bivariate metaanalysis and systematic review. Chest. 2010; 138: 817-24. PMid:20453070 http://dx.doi.org/10.1378/chest.10-0488

[60] Donnelly JP. Polymerase chain reaction for diagnosing invasive aspergillosis: getting closer but still a ways to go. Clin Infect Dis. 2006; 42: 487-9. PMid:16421792 http://dx.doi.org/10.1086/499818 